\title{
PERISTIWA TAHKIM (POLEMIK PERSELISIHAN POLITIK DAN IMPLIKASINYA)
}

\author{
Miftahur Ridho*
}

\begin{abstract}
Politics is the biggest source of Muslim division. Starting from a dispute that occurred between Ali bin Abi Talib and Muawiyab who wanted revenge for Uthman's death, a Siffin war broke out which was a new chapter in the bistory of the birth of sects which had their own political vision. There are two schools - even two tendencies which gave birth to many schools - which were born as an implication of the war, namely Shi'ah and Khawarij. Both of these streams emerge because of the same factor, namely extremity and contradiction. The appearance of the Khawarij gave a large share of the emergence and spread of Shi'ah. Extremity claims propagated by one of the streams above encourage the emergence of rival extremities from other schools. The struggle between the two schools gave rise to another stream which aimed to mediate between the two contradictory sides, namely Murji'ah, a school that dared to bring up its own vision, even though in the end one of the two firqabs was followed. In subsequent developments emerged the flow of Mu'tazilah, Qadariyyah and Jabbariyyah.
\end{abstract}

Keywords: Politics, flow, theology

\section{Pendahuluan}

Masalah politik merupakan sumber perpecahan umat Islam yang terbesar. Demikianlah yang dikatakan oleh Al-Shahrastani (wafat th.

* Dosen UIN Sunan Ampel Surabaya Prodi Sejarah Peradaban Islam 
$548 \mathrm{H}$ ) dalam bukunya al-Milal wa al-Nibal: "Dan perselisihan terbesar di antara umat adalah perselisihan mengenai imamah (kepemimpinan), karena tidak pernah pedang dihunus dalam Islam dengan alasan agama, sebagaimana (sesering) dihunusnya pedang karena imamah pada setiap zaman" ${ }^{1}$.

Peristiwa Tabkim menempati posisi yang sangat penting dalam sejarah politik pemerintahan Islam, sehingga harus dilakukan kajian obyektif terhadap kejadian yang sebenarnya. Hal tersebut amat penting, mengingat citra sebuah fakta sejarah sangat bergantung pada interpretasi terhadapnya. Dalam konteks ini, interpretasi terhadap peristiwa Tabkim telah mencemari kedudukan dan nama baik para sahabat, misalnya kisahkisah masyhur di kalangan umat Islam yang menggambarkan para sahabat yang terlibat dalam peristiwa Tabkim sebagai penipu, bersifat teledor, dan berlomba-lomba dalam merebut kekuasaan. Untuk itulah perlu dijelaskan berbagai distorsi interpretasi sejarah terkait dengan peristiwa Tabkim tersebut. Penulisan makalah ini lebih khusus dijadikan sarana untuk memahami latar belakang peristiwa tabkim, hubungan dengan kondisi sosial politik yang ada, dan menarik benang merah munculnya sekte-sekte dalam Islam, mulai yang berorientasi politik sampai pada dimensi teologi, pasca peristiwa tabkim.

\section{Kekhalifahan Ali bin Abi Thalib}

Peristiwa terbunuhnya Uthman bin Affan menyebabkan perpecahan umat Islam menjadi empat golongan, yakni: 1) pengikut Uthman, yaitu yang menuntut balas atas kematian Uthman dan mengajukan Mu'awiyah sebagai khalifah, 2) pengikut Ali, yaitu yang mengajukan Ali sebagai khalifah, 3) kaum moderat, tidak mengajukan calon dan menyerahkan urusannya kepada Allah, 4) golongan yang berpegang pada prinsip jamaah, di antaranya Sa'ad bin Abi Waqqas, Abu Ayyub al-Anshori, Usamah bin Zaid dan Muhammad bin Maslamah yang diikuti oleh 10.000 orang sahabat yang memandang bahwa Uthman dan Ali samasama sebagai pemimpin. ${ }^{2}$

1 Al-Imam Abu al-Fath Muhammad bin Abd al-Karim al-Shahrastani, al-Milal wa al-Nihal, (Beirut: Dar al-Kutub al-Ilmiyyah, tth), 13

2 Abudin Nata, Ilmu Kalam, Filsafat dan Tasawuf (Jakarta: Rajawali Press, 1995), 14 
Setelah wafatnya Uthman, Ali adalah calon terkuat untuk menjadi khalifah, karena banyak didukung oleh para sahabat senior, bahkan para pemberontak kepada khalifah Uthman mendukungnya, termasuk Abd Allah bin Saba'. ${ }^{3}$ Ali adalah putra Abi Thalib ibn Abd al-Mutthalib. Ia adalah sepupu Rasulullah Saw, yang kemudian menjadi menantunya dengan menikahi putri Rasulullah. Mahmud al-Nasir mengatakan bahwa Ali termasuk salah seorang yang baik dalam memainkan pedang dan pena, bahkan ia terkenal sebagai seorang orator. Ia juga seorang yang pandai dan bijaksana, sehingga menjadi penasihat pada zaman khalifah Abu Bakar, Umar dan Uthman. Ia mengikuti hampir semua peperangan pada zaman Nabi Muhammad Saw. Ia tidak sempat ikut membai'at Abu Bakar, karena sibuk mengurus jenazah Rasulullah Saw. ${ }^{4}$

Pengukuhan Ali bin Abi Thalib menjadi khalifah tidak semulus pengukuhan tiga khalifah sebelumnya, yaitu Abu Bakar, Umar Ibn alKhattab dan Uthman Ibn Affan. Ali dibai'at di tengah-tengah suasana berkabung atas meninggalnya Uthman, pertentangan dan kekacauan sosial politik, serta kebingungan umat Islam Madinah. Setelah Uthman terbunuh, kaum pemberontak mendatangi para sahabat senior satu per satu yang ada di kota Madinah, seperti Ali bin Abi Thalib, Talhah, Zubair, Sa'ad bin Abi Waqqas dan Abd Allah bin Umar agar bersedia menjadi khalifah, namun mereka menolak. Pada dasarnya para pemberontak maupun kaum Anshar dan Muhajirin lebih menghendaki Ali sebagai khalifah. Ia didatangi beberapa kali oleh kelompok-kelompok tersebut agar bersedia dibai'at menjadi khalifah, namun ia menolak. Ali menghendaki agar urusan itu diselesaikan melalui mushawarah dan mendapat persetujuan dari sahabat-sahabat senior terkemuka. Setelah massa rakyat mengemukakan bahwa umat Islam perlu segera memiliki pemimpin agar tidak terjadi kekacauan yang lebih besar, akhirnya Ali bersedia dibai' at menjadi khalifah ${ }^{5}$.

3 Dedi Supriyadi, Sejarah Peradaban Islam, (Bandung: CV. Pustaka Setia, 2008), 96

4 Samsul Munir Amin, Sejarah Peradaban Islam, (Jakarta: Amzah, 2009), 109. Lihat juga Hassan Ibrahim Hassan, sejarab dan Kebudayaan Islam (Yogyakarta: Kota Kembang, 1989), 59-61

5 Dedi Supriyadi, Sejarah Peradaban Islam, 93 
Ali bin Abi T \}alib dibai' at ${ }^{6}$ pada tanggal $35 \mathrm{H} / 23$ Juni $656 \mathrm{M},{ }^{7}$ oleh mayoritas rakyat dari Muhajirin dan Anshor, serta para tokoh sahabat seperti $\mathrm{T}\}$ alh $\}$ ah dan Zubair, meskipun ada beberapa orang sahabat senior yang tidak ikut membai' at Ali seperti Abd Allah bin Umar, Muhammad bin Maslamah, Sa'ad bin Abi Waqqas\}, $\mathrm{H}$ \{asan bin Thabit dan Abd Allah bin Salam yang waktu itu berada di Madinah. Ibn Umar dan Sa'ad misalnya, bersedia berbai' at kalau seluruh rakyat sudah berbai' at. ${ }^{8}$ Dengan demikian, Ali tidak dibai'at oleh kaum muslimin secara aklamasi, karena banyak sahabat senior saat itu tidak berada di kota Madinah. Mereka tersebar di wilayah-wilayah taklukan baru, di luar kota Madinah. Salah seorang tokoh yang menolak untuk membai' at Ali dan menunjukkan sikap konfrontatif adalah Mu'awiyah bin Abi Sufyan, keluarga Uthman dan Gubernur Sha $>m$. Alasan yang dikemukakan, karena Ali bertanggung jawab atas terbunuhnya Uthman.

Pemerintahan Khalifah Ali bin Abi Thalib dapat dikatakan sebagai pemerintahan yang tidak stabil karena adanya pemberontakan dari sekelompok kaum muslimin sendiri. Pemberontakan pertama diawali oleh penarikan bai' at oleh Talhah dan Zubair, karena alasan bahwa Khalifah Ali tidak memenuhi tuntutan mereka untuk menghukum pembunuh Khalifah Uthman. Penolakan Khalifah ini kemudian disampaikan kepada Siti Aishah yang merupakan kerabatnya di perjalanan pulang dari Makkah, yang tidak tahu mengenai kematian Khalifah Uthman, sementara Talhah dan Zubair dalam perjalanan menuju Basrah. Siti Aishah bergabung dengan Talhah dan Zubair untuk menentang Khalifah Ali,

${ }^{6}$ Setelah Ali bin Abi Thalib dibai'at menjadi khalifah di masjid Nabawi, ia menyampaikan pidato penerimaan jabatannya sebagai berikut:

“........Wahai manusia, kamu telah membai' atku sebagaimana yang telah kamu lakukan terhadap khalifah-khalifah terdahulu. Aku hanya boleh menolak sebelum jatuh pilihan. Setelah jatuh pilihan, penolakan tidak boleh lagi. Imam harus kuat, teguh, dan rakyat harus taat dan patuh. Bai'at terhadap diriku adalah bai'at yang merata dan umum. Barangsiapa yang mangkir darinya, terpisahlah dia dari agama Islam”. Lihat Suyuti Pulungan, Fiqh Siyasab: Ajaran, Sejarah dan Pemikiran (Jakarta: Rajawali Press, 1994), 153

7 Ali Mufrodi, Islam di Kawasan Kebudayaan Arab (Jakarta: Logos, 1997), 64

8 Ibid

9 Dedi Supriyadi, Sejarah Peradaban Islam, 94 
bisa jadi karena alasan penolakan Ali menghukum pembunuh Uthman, atau karena terpengaruh hasutan mereka berdua. Mu'awiyah turut andil pula dalam pemberontakan ini, namun hanya sebatas pada usaha untuk menurunkan kredibilitas Khalifah di mata umat Islam, dengan cara menuduh Khalifah sebagai orang yang mendalangi pembunuhan Khalifah Uthman, jika ia tidak dapat menemukan dan menghukum pembunuh yang sesungguhnya. ${ }^{10}$

Tuntutan mereka tidak mungkin segera dikabulkan oleh Khalifah Ali karena dua hal. Pertama, karena tugas utama yang mendesak dilakukan dalam situasi kritis yang penuh intimidasi seperti itu ialah memulihkan ketertiban dan mengonsolidasikan kedudukan kekhalifahan. Kedua, menghukum para pembunuh bukanlah perkara mudah. Khalifah Uthman tidak dibunuh oleh hanya satu orang, melainkan banyak orang dari Mesir, Irak dan Arab, yang secara langsung terlibat dalam perbuatan makar tersebut. ${ }^{11}$

Pada dasarnya Khalifah Ali telah berusaha untuk menghindari pertumpahan darah dengan mengajukan kompromi, tetapi beliau tidak berhasil, sampai akhirnya terjadi pertempuran antara Khalifah Ali bersama pasukannya dengan Talhah, Zubair dan Aishah bersama pasukannya. Perang ini terjadi pada tahun $36 \mathrm{H}$. Talhah dan Zubair terbunuh ketika hendak melarikan diri dan Aishah dikembalikan ke Madinah. Peperangan ini terkenal dengan nama "Perang Jamal" (Perang Unta), karena dalam pertempuran tersebut, Aishah, istri Nabi Saw mengendarai unta. Dalam pertempuran tersebut 20.000 kaum muslimin gugur. ${ }^{12}$

Perang unta menjadi sangat penting dalam catatan sejarah Islam, karena peristiwa itu memperlihatkan sesuatu yang baru dalam Islam, yaitu untuk pertama kalinya seorang khalifah turun ke medan perang untuk memimpin langsung angkatan perang, dan justru bertikai melawan saudara sesama muslim.

Sesudah menyelesaikan gerakan Talhah dan kawan-kawan, pusat kekuasaan Islam dipindahkan ke kota Kufah. Sejak itu berakhirlah Madinah sebagai ibu kota kedaulatan Islam dan tidak ada lagi seorang khalifah yang berkuasa berdiam di sana. Sekarang, Ali adalah pemimpin

\footnotetext{
${ }^{10}$ Ibid, 97

${ }^{11}$ Samsul Munir Amin, Sejarab Peradaban Islam, 110-111

${ }^{12}$ Ibid, 111
} 
dari seluruh wilayah Islam, kecuali Shiriah yang dikuasai oleh Mu'awiyah. ${ }^{13}$

Dengan dikuasainya Shiriah oleh Mu'awiyah yang secara terbuka menentang Khalifah, memaksa Khalifah Ali untuk bertindak. Pertempuran sesama muslim terjadi lagi, yaitu antara angkatan perang Khalifah Ali dan pasukan Mu'awiyah di kota tua Siffin, dekat sungai Eufrat, pada tahun $37 \mathrm{H}$. Khalifah Ali mengerahkan 50.000 pasukan untuk menghadapi Mu'awiyah. Sebenarnya pihak Mu'awiyah telah terdesak kalah, dengan 7000 pasukannya terbunuh, yang menyebabkan mereka mengangkat al-Qur'an sebagai tanda damai dengan cara tabkim. ${ }^{14}$

\section{Perjanjian Tahkimdan Perundingan antara Dua Juru Penengah}

Konflik politik antara Ali bin Abi Thalib dengan Mu'awiyah Ibn Abi Sufyan diakhiri dengan tabkim. ${ }^{15}$ Tawaran perdamaian dengan cara Tahkimini diterima oleh Ali, agar tidak semakin banyak yang menjadi korban akibat perang saudara dan demi kemaslahatan umat Islam. Dari pihak Ali diutus seorang ulama yang terkenal sangat jujur, yaitu Abu Musa al-'Ash'ari, sedangkan dari pihak Mu'awiyah diutus seorang yang terkenal sangat cerdik dalam berpolitik, yaitu 'Amr Ibn 'As. ${ }^{16}$ Para pemuka kedua belah pihak menyaksikan secara langsung pelaksanaan tabkim. Peristiwa itu terjadi pada malam Rabu, 13 hari terkhir bulan S\}afar tahun $37 \mathrm{H}$. Naskah perjanjian Tabkim itu adalah:

"Bismillah al-Raman al-Rahim. Inilah keputusan yang ditetapkan pihak Ali bin Abi Thalib dan pihak Mu'awiyah bin Abi Sufyan. Ali bertindak atas nama penduduk Kufah dan orang-orang yang mendukungnya, sedangkan Mu'awiyah bertindak atas nama penduduk Sham beserta setiap orang yang mendukungnya. Kami akan tunduk pada hukum Allah dan kitab-Nya. Tidak ada sesuatu pun selain dari kedua hukum

\section{${ }^{13}$ Ibid}

${ }^{14}$ Dedi Supriyadi, Sejarah Peradaban Islam, 97-98

${ }^{15}$ Perkataan al-Tabkimsecara bahasa adalah mas\} dar dari kata hakkama yang berarti melantik seseorang menjadi hakim untuk mengadili sesuatu perkara. Lihat Ibrahim Anis, dkk, Al-Mu'jam al-Wasit (Beirut: Dar al-Ma'rifah, t.th), 190. Dengan demikian Tabkimdalam konteks ini adalah persetujuan dari pihak Khalifah Ali dan Mu'awiyah untuk menerima keputusan kedua hakim atau pengadil yang dilantik dalam menyelesaikan perselisihan antara mereka.

${ }^{16}$ Harun Nasution, Islam Ditinjau dari Berbagai Aspek (Jakarta: UI Press, 1986), 
tersebut yang yang dapat mempersatukan kami. Kitab Allah - mulai dari awal sampai penutupnya- berada di antara kami. Hidup dan mati kami akan mengikuti apa yang telah digariskannya. Apapun yang dijumpai dalam kitab Allah, keduanya, yaitu Abu Musa alAsh'ari Abd Allah bin Qais dan 'Amr bin al-'As\} al-Quraishy, akan mengamalkannya. Andaikata tidak dijumpai di dalamnya, maka yang menjadi pegangan selanjutnya adalah al-Sunnah yang adil, yang komprehensif dan tidak memecah belah......"17.

Sedangkan dialog yang terjadi antara kedua juru damai adalah sebagaima riwayat Imam al-Tabari dari Abu Mukhnif, sebagai berikut:

"Telah menceritakan kepadaku Abu Jannab al-Kalby bahwa ketika 'Amr bin 'As\} dan Abu Musa bertemu di Dumah al-Jandal, 'Amr memulai pembicaraan, "Wahai Abu Musa! Engkau adalah sahabat Rasulullah dan usiamu lebih tua daripadaku. Bicaralah lebih dahulu, kemudian giliranku". "Amr memang biasa menunjuk Abu Musa untuk bertindak terlebih dahulu dalam setiap persoalan yang mereka hadapi. Dengan tindakan itu, 'Amr bermaksud agar Abu Musa terlebih dahulu mencopot kekhalifahan Ali bin Abi Thalib. Keduanya kemudian terlibat dalam diskusi, tetapi tidak pernah sepakat. 'Amr berkehendak mengangkat Mu'awiyah sebagai khalifah, tetapi Abu Musa menolaknya. Ia lalu mengajukan anak Mu'awiyah, Yazid, tetapi Abu Musa pun menolaknya. Abu Musa sendiri mengajukan 'Abd Allah bin Umar, tetapi 'Amr menolaknya. 'Amr akhirnya berkata kepada Abu Musa, "Katakanlah apa pendapatmu?". Abu Musa menjawab, "Pendapatku adalah menurunkan kedua pemimpin ini dari kursi kekhalifahan. Selanjutnya kita serahkan permasalahan ini pada musyawarah kaum muslimin. Biarkan mereka memilih pemimpin yang dikehendakinya". 'Amr menjawab "Pendapat itulah yang ingin aku sampaikan."

Kedua orang itu kemudian menemui kaum muslimin yang sudah berkumpul. 'Amr berkata kepada Abu Musa: "Umumkanlah kepada mereka tentang persoalan yang telah kita sepakati dan setujui!” Abu Musa kemudian berkata: "Aku dan 'Amr telah sepakat terhadap satu persoalan yang mudah-mudahan Allah menjadikannya sebagai kemaslahatan bagi

${ }^{17}$ Al-Thabari dalam Muhammad Mahzum, "Tahqiq Mawaqif al-Sahabah Fi al-Fitnah" Diterj. Oleh: Rosihon Anwar, Meluruskan Sejarab Islam (Bandung: CV. Pustaka Setia, 1994), 31 
umat ini." "Amr berkata: "Engkau benar, wahai Abu Musa, silakan engkau dulu yang mengumumkan.” Ketika Abu Musa maju ke depan hendak bicara, Ibnu 'Abbas berkata: "Celakalah engkau Abu Musa! Demi Allah, aku yakin ia telah menipumu. Apabila kalian telah sepakat, biarkanlah ia bicara dahulu, kemudian giliran engkau karena ia seorang pengkhianat. Aku tidak percaya ia telah merelakan apa yang engkau katakan telah disepakati. Apabila engkau berbicara di hadapan mereka ia akan mengingkari pembicaraanmu." Abu Musa tampaknya tidak sadar dengan peringatan Ibn 'Abbas dan ia berkata; "Benar kami telah sepakat.'

Abu Musa kemudian maju. Setelah memanjatkan pujian kepada Allah, ia berkata: "Wahai manusia! Kami telah memikirkan umat ini dan kami tidak melihat hal yang lebih maslahat dari umat ini. Tidak ada yang menyakiti bagi umat ini, kecuali apa yang telah menjadi kesepakatanku dan kesepakatan 'Amr, yaitu kami mencopot kepemimpinan Ali dan Mu'awiyah. Umat inilah yang selanjutnya akan menangani persoalan ini dan memilih pemimpin yang disukainya. Aku sendiri telah mencopot Ali dan Mu'awiyah. Aku serahkan urusan kepada kalian. Pilihlah siapa yang paling pantas menjadi khalifah." Setelah selesai berbicara, ia turun dari mimbar dan 'Amr kemudian maju untuk berbicara. Setelah memanjatkan puji kepada Allah, ia berkata: "Kalian sudah mendengar ucapannya. Ia mencopot karibnya dan aku pun setuju mencopotnya seperti yang telah dilakukannya. Dan sekarang aku menetapkan karibku, Mu'awiyah sebagai khalifah. Ia adalah wali Uthman bin 'Affan dan orang yang menuntut atas kematiannya. Dialah di antara manusia yang paling berhak menggantikan posisinya."

Mendengar ucapannya, Abu Musa berdiri dan menghardik: "Apa yang engkau lakukan, Allah tidak memberkatimu. Engakau telah berkhianat dan berdusta. Engaku bagaikan anjing. Bila diperhatikan, ia menjulurkan lidahnya. Bila tidak diperhatikan, ia pun menjulurkan lidahnya." "Amr menjawab: "Engkau bagaikan Himar yang membawa setumpuk buku." Shuraih bin Hani' mendatangi 'Amr dan memukulnya dengan cambuk, dan anak 'Amr membalas mencambuknya. Kaum muslimin pun berdiri untuk melerai pertikaian. Setelah peristiwa itu itu Shuraih berkata: "Aku tidak menyesal memukul 'Amr, dan aku akan melakukannya kembali nanti." Penduduk Sham kemudian memohon Abu Musa pulang, Ia lalu 
mengendarai kudanya menuju Makkah." ${ }^{18}$

Ibn 'Abbas mengomentari peristiwa di atas dengan mengatakan: "Mudah-mudahan Allah mencela pendapat Abu Musa. Aku telah mengingatkan dan menyuruhnya untuk berpikir kembali, tetapi ia tidak menanggapinya." Abu Musa menjawab: "Ibn 'Abbas telah mengingatkanku atas tipuan si fasik itu ("Amr bin "Ash), tetapi aku mempercayainya. Aku kira ia tidak akan merusak kemaslahatan umat." 'Amr dan penduduk Sham akhirnya pergi menemui Mu'awiyah untuk menyatakan selamat atas kekhalifahannya, sedangkan Ibn 'Abbas dan Shuraih menemui Ali. Ketika menunaikan shalat subuh, dalam qunutnya Ali berdoa, "Ya Allah, laknatlah Mu'awiyah, 'Amr, Abu al-A'war alSalami, Habib Ibn Maslamah, Abd al-Rahman bin Khalid, al-Dahak bin Qais dan al-Walid Ibn 'Uqbah.” Ketika doa Ali r.a disampaikan kepada Mu'awiyah, ia pun dalam qunu>t shalat $S\{$ ubuhnya melaknat Ali, Ibn 'Abbas, al-Ashtar, Hasan dan Husain, kedua anak Ali r.a. ${ }^{19}$

\section{Studi Kritis Riwayat Tahkim}

Menurut Dr. Muhammad Mahzum dalam kitabnya Tahqiq Mawaqif al-Sahabah fi al-Fitnah dalam mengomentari riwayat Tabkim tersebut, memperlihatkan adanya dua kecacatan, yaitu sanadnya da' if dan matannya kacau (mudtarib). Dilihat dari segi sanadnya, di dalamnya terdapat dua perawi yang diragukan keadilannya, yaitu Abu Mukhnif Lauth bin Yahya dan Abu Jannab al-Kalbi. Yang disebutkan pertama bukanlah orang tepercaya (thiqab), sedangkan yang kedua adalah seorang yang da'if. Al-Bukhari dan Abu Hatim pun berkata bahwa Yahya al-Qattan telah men-dai'f-kannya. Penilaian yang sama diberikan oleh al-Darimi dan al-Nasa'i. $^{20}$

Berdasarkan tinjauan matan riwayat tahkim tersebut, memperlihatkan tiga tema utama, yaitu;

a. Perselisihan antara Ali bin Abi Talib dan Mu'awiyah

Para sejarawan sepakat bahwa pemicu perselisihan antara Ali dan Mu'awiyah adalah tuntutan qis\}as bagi pembunuh Uthman.

Mu'awiyah beranggapan bahwa Ali sengaja tidak melaksanakan

\footnotetext{
${ }^{18}$ Ibid, 38-40

${ }^{19}$ Ibid, 40

${ }^{20}$ Ibid, 40-41
} 
kewajiban untuk mengqis $\}$ as para pembunuh Uthman. Itu sebabnya, ia menolak membai'at dan menaati Ali r.a. Mu'awiyah menuntut pelaksanaan qishas sebelum membai'at Ali, sebab ia merasa berhak atas tuntutan itu karena kekerabatannya dengan Uthman.

Ali menganggap Mu'awiyah dan para pengikutnya sebagai pemberontak karena sikapnya yang tidak mau membai'at Ali dan melaksanakan kebijakan-kebijakan politisnya di seluruh dataran Sham, padahal Ali merupakan Imam yang wajib ditaati. Mu'awiyah tidak hanya sekedar mengingkari kekhalifahan Ali, ia bahkan dengan ijtihadnya- berpendapat bahwa tuntutan terhadap pembunuh Uthman lebih utama daripada bai' at terhadap Ali. Sikap Muawiyah dalam persoalan tuntutan dapat dibenarkan, tetapi sikapnya yang lebih mementingkan tuntutannya daripada bai' at kepada Ali adalah keliru. ${ }^{21}$ Dengan demikian, pokok perselisihan Tabkim bukanlah pada perebutan kekuasaan khilafah, nmelainkan memutuskan tuntutan pelaksanaan qishas bagi pembunuh Uthman, sebagaimana riwayatriwayat sejarah yang sudah masyhur berkembang di kalangan umat Islam. Pemahaman ini sekaligus mengoreksi kesalahan riwayat Tabkim terdahulu.

b. Posisi Ali dan Mu'awiyah

Setelah Uthman terbunuh, dan Ali menduduki kursi kekhilafahan, Mu'awiyah tidak mengakuinya, akhirnya ia mengasingkan diri. Dengan demikian Mu'awiyah kehilangan kekuasaan formalnya di Sham, meskipun ia masih memiliki pengaruh di kota tersebut. Ia bagaikan seorang pemimpin tidak resmi yang memutuskan persoalanpersolan di sana, yang sangat ditaati oleh penduduk Sham. ${ }^{22}$

Apabila fakta sejarahnya demikian, maka pencopotan jabatan Mu'awiyah -sebagaimana riwayat Tabkim- bukan pada tempatnya, karena ia bukan lagi seorang gubernur di Sham. Hal ini juga menjadi bukti kelirunya tentang kisah-kisah tahkim, yang banyaqk tersebar di kalangan umat Islam.

c. Kepribadian Abu Musa Al-Ash'ari dan 'Amr bin 'Ash

Pendapat yang mengatakan bahwa Abu Musa al-Ash'ari dalam peristiwa tahkim menjadi korban kelicikan 'Amr bin 'As, telah

\footnotetext{
${ }^{21}$ Ibid, 42

${ }^{22}$ Ibid.
} 
menafikan fakta-fakta integritasnya yang menggambarkan keutamaan, kecerdasan, kefaqihan, dan keagamaan yang dimiliki Abu Musa. Buktinya, ia diangkat sebagai dewan kehakiman semenjak zaman Rasulullah dan sebagai gubernur pada masa Umar, Uthman dan Ali. Para sahabat dan kebanyakan ulama dari kalangan tabi' in mengenal Abu Musa al-Ash'ari sebagai orang yang dalam ilmunya, bijak dalam menentukan hukum, dan cerdas dalam memberi keputusan. ${ }^{23}$

Seperti halnya Abu Musa, 'Amr bin 'As\} dikenal sebagai salah seorang hakim yang cerdas di kalangan masyarakat Arab. Rasulullah pernah menyuruhnya untuk mengadili dua orang yang sedang berselisih di hadapan beliau sendiri. Shaikh Ibn Taimiyyah dalam Fatawanya menyebutkan bahwa tidak ada seorang ulama salaf pun yang menuduh 'Amr bin 'As\} dan Mu'awiyah sebagai orang yang munafik dan penipu. ${ }^{24}$

Uraian tersebut menunjukkan bahwa Abu Musa al-Ash'ari dan 'Amr bin 'Ash adalah dua orang sahabat yang memiliki intregitas dan kredibilitas yang tinggi dalam persoalan yang dibebankan kepada keduanya sebagai juru tengah. Dengan demikian, tidak dimungkinkan adanya i'tikad yang tidak baik dari keduanya dalam proses perdamaian itu, melainkan kemaslahatan bagi kaum muslimin secara keseluruhan. Tidak mungkin Abu Musa tertipu oleh tipu muslihat 'Amr bin 'Ash, dan sebaliknya, 'Amr juga tidak mungkin mengingkari apa yang telah ia sepakati, karena hal ini merupakan tindakan tercela.

d. Keputusan juru tengah yang sebenarnya

Tidak diragukan lagi bahwa pemicu perselisihan yang diserahkan kedua juru penengah kepada umat dan ahli Shura adalah tentang pembunuhan Uthman. Itulah fakta yang sesuai dengan dasar-dasar sebagaimana penjelasan terdahulu. Lagi pula, Mu'awiyah pada saat itu tidak mengaku sebagai khalifah, dan tidak mengingkari hak Ali menduduki kursi khalifah. Ia hanya menolak membai'at Ali dan menolak melaksanakan perintah-perintahnya di Sham, dengan pertimbangan bahwa hukum Allah adalah yang dominan berlaku di

\footnotetext{
${ }^{23} \mathrm{Ibid}, 43$

${ }^{24}$ Ibid, 44-48
} 
sana, bukan hukum undang-undang pemerintah. Kesimpulan itu berdasarkan pengalamannya ketika ia menjadi gubernur di Sham serlama kerang lebih 20 tahun.

\section{Implikasi Setelah Fitnah}

Akhir perang Siffin merupakan babak baru sejarah lahirnya aliranaliran yang memiliki visi politik masing-masing. Ada dua aliran -bahkan dua kecenderungan yang melahirkan banyak aliran- yang lahir sebagai implikasi dari peperangan itu, yaitu Shi' ah dan Khawarij. Kedua aliran ini muncul karena satu faktor yang sama, yaitu ekstrimitas dan kontradiktif. Kemunculan Khawarij memberi saham besar bagi kemunculan dan penyebaran Shi'ah. Klaim ekstrimitas yang dipropagandakan salah satu aliran di atas mendorong munculnya ektrimitas tandingan dari aliran yang lainnya.

Pergumulan antara kedua aliran itu memunculkan satu aliran lain yang bertujuan menengahi dua sisi yang kontadiktif itu, yaitu Murjiah, sebuah aliran yang berani memunculkan visinya sendiri, meskipun pada akhirnya mengikuti salah satu dari dua firqah di atas.

1. Aliran Khawarij

Peristiwa Tabkim antara Ali dan Mu'awiyah memicu lahirnya aliranaliran Islam yang berdimensi politik, di antaranya adalah aliran Khawarij. Mereka sebenarnya para pengikut Ali yang kemudian keluar dari barisan Ali bin Abi Thalib, karena tidak setuju dengan sikap Ali mengenai Tabkim (arbitrase) sebagai jalan keluar dalam penyelesaian persengketaan antara Khalifah Ali dengan Mu'awiyah bin Abi Sufyan. ${ }^{25}$ Mereka berpendapat bahwa semua orang yang terlibat dalam peristiwa Tabkim sebagai pendosa besar dan kafir yang wajib diperangi. Atas dasar inilah seorang pengikut mereka, yaitu Ibn Muljam, akhirnya berhasil membunuh Ali bin Abi Thalib pada tanggal 17 Ramadhan $40 \mathrm{H}(661 \mathrm{M}){ }^{26}$

2. Aliran Shi'ah

Shi'ah merupakan para pengikut dan pendukun Ali yang muncul setelah terjadinya peristiwa tabkim. Golongan ini memiliki pandangan

${ }^{25}$ Muhammad Ahmad, Taubid Ilmu Kalam (Bandung: Pustaka Setia, 1998), 151

${ }^{26}$ Samsul Munir Amin, Sejarah Peradaban Islam, 112 
bahwa Ali adalah kahlifah yang harus ditaati, dan menganggap Mu'awiyah beserta penduduk Sham adalah para pemberontak yang dituntut untuk kembali kepada jamaah Islam walaupun dengan menggunakan pedang. ${ }^{27}$

3. Aliran Murji'ah

Kaum Murji'ah muncul akibat adanya pertentangan politik dalam Islam, yakni peristiwa tabkim. Dalam suasaana yang demikian, kaum ini muncul dengan corak dan gaya tersendiri. Mereka bersikap netral, tidak berkomentar dalam praktek kafir atau tidaak bagi golongan yang bertentangan. Mereka tidak berpendapat siapa yang benar dan yang salah, tetapi berpandangan lebih baik menunda (arja'a). maksudnya persoalan tersebut dapat diselesaikan pada hari perhitungan, sehingga sikapnya menyerahkan hukum kafir atau tidaknya seseorang kepada Allah Swt. ${ }^{28}$

Pada perkembangan selanjutnya, orientasi berbagai aliran yang muncul setelah adanya fitnah itu, berubah dari motif politik menjadi aliran teologi (kalam). Berangkat dari pergeseran nilai orientasi ini, pada masa selanjutnya muncul aliran-aliran baru di luar tiga sekte yang sudah ada, misalnya paham Mu'tazilah, Qadariyah, Jabbariyah, Ash'ariyah dan Maturidiyah.

\section{Kesimpulan}

Dari uraian tentang peristiwa Tabkimdan berbagai implikasinya tersebut, dapat disimpulkan bahwa:

1. Pemicu perselisihan antara Ali dan Mu'awiyah adalah tuntutan qis $\}$ as bagi pembunuh Uthman. Mu'awiyah beranggapan bahwa Ali sengaja tidak melaksanakan kewajiban untuk mengqis $\}$ as para pembunuh Uthman. Itu sebabnya, ia menolak membai' at dan menaati Ali r.a. Khalifah Ali sendiri menganggap Mu'awiyah dan para pengikutnya sebagai pemberontak karena sikapnya yang tidak mau membai'at Ali dan menolak melaksanakan kebijakan-kebijakan politisnya di seluruh dataran Sham, padahal Ali merupakan Imam yang wajib ditaati.

2. Ali bin Abi Thalib menerima Tabkimkarena ia tidak ingin korban

\footnotetext{
${ }^{27}$ Muhammad Mahzum, Meluruskan Sejarah Islam, 79

${ }^{28}$ Muhammad Ahmad, Taubid Ilmu Kalam, 159
} 
bertambah banyak akibat perang saudara, meskipun pada faktanya Ali dan pasukannya sudah berhasil memukul mundur Mu'awiyah dan pasukannya.

3. Peristiwa Tabkimmenjadi sebab munculnya golongan-golongan baru seperti Khawarij, Shi'ah, dan Murji'ah atas dasar motif politis. Pada perkembangan selanjutnya, orientasi berbagai aliran itu berubah menjadi aliran teologi (kalam), yang menjadi embrio munculnya aliran-aliran teologi lainnya, seperti Mu'tazilah, Qadariyah, Jabbariyah, Ash'ariyah dan Maturidiyah. 


\section{Daftar Pustaka}

Ahmad, Muhammad. Taubid Ilmu Kalam. Bandung: Pustaka Setia, 1998. Anis, Ibrahim dkk. al-Mu'jam al-Wasit. Beirut: Dar al-Ma'rifah, t.th.

Hassan, Hassan Ibrahim. Sejarah dan Kebudayaan Islam. Yogyakarta: Kota Kembang, 1989.

Mahzum, Muhammad "Tahqiq Mawaqif al-Sahabah Fi al-Fitnah" Diterj. Oleh: Anwar, Rosihon. Meluruskan Sejarah Islam. Bandung: CV. Pustaka Setia, 1994.

Muhammad, Abu al-Fath bin Abd al-Karim al-Shahrastani. Al-Milal Wa Al-Nibal. Beirut: Dar Al-Kutub al-Ilmiyyah, t.th.

Munir Amin, Samsul. Sejarah Peradaban Islam. Jakarta: Amzah, 2009.

Nasution, Harun. Islam Ditinjau dari Berbagai Aspek. Jakarta: UI Press, 1986.

Pulungan, Suyuti. Fiqh Siyasah Ajaran, Sejarah dan Pemikiran. Jakarta: Rajawali Press, 1994.

Supriyadi, Dedi. Sejarah Peradaban Islam. Bandung: CV. Pustaka Setia, 2008. 